\title{
Relação entre a prática da estratégia investigativa em sala de aula e o desenvolvimento do potencial criativo em estudantes
}

\author{
Vanessa Pederiva ${ }^{1}$ \\ Jacqueline Silva da Silva²
}

\section{Resumo}

Através de uma pesquisa bibliográfica, de caráter qualitativo, este estudo buscou averiguar de que forma a investigação, quando utilizada como estratégia de ensino em sala de aula, pode auxiliar no desenvolvimento do potencial criativo dos alunos. Entende-se que a criatividade é necessária em certo nível para toda pessoa, a fim de identificar e solucionar problemas que surgem no cotidiano. Para tanto, ao fazer uso da prática investigativa, o professor instigará seus alunos a se posicionarem perante situações, construírem seu conhecimento com a interação de todos, proporcionando autonomia e senso crítico em seus alunos e consequentemente, o desenvolvimento da capacidade criativa.

Palavras-chave: Investigação; Criatividade; Sala de aula.

\section{Relation between the practice of the investigative strategy in the classroom and the development of creative potential in students}

\begin{abstract}
Through a bibliographical research of a qualitative nature, this study sought to investigate how the investigation, when used as a teaching strategy in the classroom, can help in the development of students' creative potential. It is understood that creativity is necessary at a certain level for every person to identify and solve problems that arise in everyday life. In order to do so, in making use of the investigative practice, the teacher will instigate his students to position themselves before situations, to build their knowledge with the interaction of all, providing autonomy and critical sense in their students, and consequently, the development of creative capacity.

Keywords: Scientific inquiry; Criativity; Classroom.
\end{abstract}

\section{Introdução}

O presente estudo originou-se de um projeto de pesquisa intitulado "Princípio da Investigação e Pedagogia Empreendedora", vinculado ao Programa de Pós-graduação em Ensino de uma Universidade do interior do Rio Grande do Sul. O projeto de pesquisa teve como um dos objetivos analisar como o princípio da investigação se manifesta no cotidiano de alunos e

\footnotetext{
${ }^{1}$ Universidade do Vale do Taquari/Univates. Lajeado/RS. Endereço eletrônico: vpederiva@universo.univates.br

${ }^{2}$ Universidade do Vale do Taquari/Univates. Lajeado/RS. Endereço eletrônico: jacqueh@univates.br
} Periódico Horizontes - USF - Itatiba, SP-Brasil - e019009 
professores da Educação Infantil e do Ciclo de Alfabetização.

A partir de leituras de referenciais teóricos sobre o tema, percebeu-se que a investigação é um método que, quando utilizado em sala de aula pelo professor, estimula o aluno a desenvolver sua autonomia, seu senso crítico e sua criatividade. Dessa forma, quando o aluno está investigando, ele se posiciona, se coloca perante suas dúvidas, pensando e problematizando suas pesquisas, hipóteses e resultados.

Diante disso, a partir de um levantamento de referenciais bibliográficos, o presente estudo objetivou responder a seguinte questão: de que forma a utilização de estratégias investigativas em sala de aula pode auxiliar os alunos a desenvolverem sua criatividade?

É possível perceber nas escolas, que o ensino tradicional vem sendo questionado, fazendo com que os professores problematizem os modos de ensinar e de aprender. Neste artigo buscase apresentar a estratégia da investigação como uma possibilidade de mudança, instigando os alunos a buscarem por respostas, auxiliando-os no desenvolvimento da sua criatividade, favorecendo um ensinar e aprender mais significativo para alunos e professores.

A criatividade tem sido cada vez mais necessária, principalmente aos profissionais de início de carreira, pois precisam inovar o modo de atuar dentro de sua profissão, para conseguirem adquirir espaço no mercado de trabalho. Essa necessidade se apresenta pelo fato de que vivemos em uma sociedade efêmera, onde precisamos pensar e agir constantemente de forma inovadora e criativa. Desse modo, a utilização da estratégia investigativa, é uma possibilidade.

\section{Metodologia}

O presente estudo segue uma abordagem qualitativa, na qual se caracteriza por buscar no meio bibliográfico, informações que se constituíram como fonte relevante de conhecimento para responder ao problema de pesquisa, já apresentado. A pesquisa de cunho bibliográfico foi realizada a partir do levantamento de referenciais teóricos já analisados e publicados, os quais foram levantados entre os meses de Março e Dezembro de 2017. Conforme Gil (2006), esse tipo

Periódico Horizontes - USF - Itatiba, SP-Brasil - e019009 
de pesquisa possibilita que as informações sejam obtidas de materiais impressos como livros, revistas, teses, dissertações entre outros, assim como de materiais mídias digitais como CDs, discos e materiais publicados na internet.

Destacamos que a pesquisa bibliográfica não é uma repetição do que já foi dito, escrito e publicado, possibilitando a discussão de um determinado assunto sob outra perspectiva e permitindo que este novo autor consiga chegar a conclusões inovadoras (LAKATOS; MARCONI, 2010). Desse modo, em se tratando de um projeto de pesquisa em andamento, a base para o referencial teórico sobre investigação já se tinha para este estudo.

Já para o embasamento teórico sobre criatividade, foram utilizadas duas plataformas de dados para pesquisa, Scientific Electronic Library Online - SciELO e Periódicos Eletrônicos em Psicologia - PEPSIC, onde, utilizando o termo "criatividade" como descritor, sem delimitação de ano de publicação, a partir dos títulos dos artigos, foram selecionados 35 para a leitura dos resumos. Apenas três artigos se encaixaram nos critérios utilizados para a escrita do embasamento teórico, os quais se referiam ao desenvolvimento, treinamento e estimulação da criatividade. Além disso, foi utilizada a estratégia de localização de estudos que foram citados nos artigos, como forma de pesquisa de referencial teórico, sendo selecionados um artigo e um livro. Também se utilizou o site da biblioteca da IES, a qual o projeto de pesquisa está vinculado, para localizar materiais sobre criatividade. A busca totalizou 160 livros, dentre os quais foram selecionados três para auxiliar no embasamento teórico deste estudo.

\section{Investigação}

Em sala de aula, quando o professor propõe um determinado assunto a ser trabalhado com os alunos, é possível utilizar diversas estratégias como por exemplo, a investigação. O trabalho investigativo é uma estratégia de ensino que pode ser utilizada de forma a beneficiar o trabalho do docente em sala de aula, no qual abre espaços para problematizações por parte de todos envolvidos, dando um significado aos processos de ensinar e aprender dos estudantes. Dessa forma, a construção do conhecimento se dá de forma coletiva, entre professor, alunos e 
escola.

Segundo o estudo de Ferraz e Sasseron (2017) que complementa a ideia de que é o professor quem deve proporcionar ao estudante a utilização da investigação como uma estratégia, disponibilizando materiais e conhecimentos para que o aluno se envolva, produzindo assim um ensino por investigação, com mais autonomia e participação por parte do estudante nos seus processos de ensino e de aprendizagem.

A importância de se estudar sobre a investigação em sala de aula iniciou-se na década de 60, no século passado. Diferente do ensino tradicional, em que o professor leva o material a ser estudado para a sala de aula, onde os estudantes apenas recebem o conhecimento, reproduzindo-o ao longo da sua vida, o ensino por investigação busca proporcionar a autonomia do estudante, sendo esse o principal responsável pela sua própria aprendizagem (MUMFORD; LIMA, 2007).

A partir da abordagem do planejamento no enfoque emergente, Silva (2011) define a investigação não como uma atitude restrita ao ambiente acadêmico, mas como algo cotidiano que busca encontrar estratégias para determinados problemas, sendo que crianças e adultos realizam a prática investigativa como uma atitude existencial. Para a autora, investigar é algo que se faz desde a infância, quando exploramos pequenos objetos para assim conhecermos o mundo à nossa volta. Com isso, pode-se pensar que a investigação acontece quando nos deparamos frente a um problema, seja relacionado a um tema de pesquisa, ou do dia-a-dia. Para tanto, uma atitude investigativa propõe que se resolva utilizando conhecimento anterior, mas de uma forma criativa e inovadora.

No trabalho com a investigação, o professor pode explicar aos seus alunos sobre teorias, hipóteses, observações, evidências e conclusões, assim como questionamentos a serem resolvidos e sugerir materiais para tal. Entretanto, deve deixar a cargo do aluno o trabalho de investigar, a fim de que ele chegue às respostas aos seus problemas, através de suas próprias conclusões, e se necessário, buscando auxílio no professor (DEBOER, 2006; AZEVEDO, 2009).

O professor ao auxiliar seus estudantes e dar-Ihes a oportunidade de realizar trabalhos investigativos, estará corroborando para o desenvolvimento da autonomia dos seus alunos, com

Periódico Horizontes - USF - Itatiba, SP-Brasil - e019009 
interesse de descobrir coisas novas, sem medo de errar e aprender através do erro. Com isso, esses alunos tornar-se-ão adultos que, tanto na vida acadêmica quanto na pessoal, terão a possibilidade de identificar e resolver seus problemas do dia-a-dia de forma autônoma, inovadora e criativa.

\section{Criatividade}

Acredita-se que toda pessoa tem capacidade e potencialidades dentro de si para fazer coisas consideradas inovadoras. No entanto, o lado criativo se desenvolve de diferentes formas em cada sujeito, de modo que, para uns, é mais fácil acessá-lo. Nesse sentido, todos possuem capacidade para desenvolver a criatividade, para isso é importante que estejam em um contexto social e cultural em que esse processo se faça necessário (WECHSLER, 1998; TUDDA; SANTOS, 2011) ou que Ihes sejam oportunizadas situações que instiguem o potencial criativo.

Nesse sentido, acreditamos que a escola seja um dos espaços que possibilite esse potencial, uma vez que nela o contato da criança com materiais diversos - massa de modelar, sucata, tintas, livros, entre outros - e com estratégias de ensino que lhe favoreçam o pensar, problematizar, refletir e levantar hipóteses sobre suas dúvidas e anseios, são oportunizados.

Contudo, não apenas na escola, com crianças e adolescentes é possível utilizar a investigação como uma estratégia a fim de incentivar a autonomia e a criatividade no estudante, mas também no ensino superior. Conforme estudos feitos por Alencar (1997) e Nakano (2011) a universidade auxilia no desenvolvimento do potencial criativo de seus estudantes, a partir da postura do professor, ao instigar os alunos a refletirem, problematizarem, procurarem por respostas e fazerem perguntas ainda não exploradas. O próprio contexto universitário ao dar autonomia ao estudante fazendo que este busque pelo conhecimento, permite que o aluno dê a sua contribuição em sala de aula, para a construção do seu próprio conhecimento, e dos colegas, também estimula que o aluno explore caminhos até então desconhecidos por ele, ampliando assim a sua rede de pensamentos, instigando a criatividade.

Vale pontuar aqui que, a criatividade referida neste trabalho, não se trata de uma Periódico Horizontes - USF - Itatiba, SP-Brasil - e019009 
criatividade artística já desenvolvida na sua totalidade, nos quais pintores, escritores, desenhistas, por exemplo, precisam ter desenvolvida para estar sempre inovando em seu trabalho, criando coisas novas o tempo todo (GARDNER, 1999). Mas sim, uma criatividade que todas as pessoas precisam ter desenvolvida de alguma forma, possibilitando a autonomia para lidar com as situações problema que nos surpreendem no cotidiano.

Um exemplo para demonstrar sobre a resolução de problemas de forma criativa, Alves (2007) em seu livro Estórias de quem gosta de ensinar, refere-se sobre a criação do iglu, o fato de alguém ter construído um iglu, mesmo sendo feito de gelo, pode manter o calor dentro de si. Diante desse exemplo, pode-se refletir sobre o fato de que criar algo novo e pensar para além do que alguém já o fez, requer observação do meio e do espaço a que se destina a criação, a fim de resolver determinado problema, assim como, utilizar os materiais que se tem disponível no momento e avaliar o que é possível fazer com o que possui.

Por outro lado, pode-se pensar que, se as crianças, em tenra idade, possuem a oportunidade de descobrir sobre seu mundo, fazendo isso de modo livre sem direcionamento por parte de um adulto, conseguirão adquirir um grande "capital de criatividade", o qual será de muito valor ao longo de sua vida. Contudo, se as crianças são privadas das atividades de descoberta e levadas a apenas uma direção, ou cegamente sobrecarregadas de que existe uma única resposta correta, ou ainda, que essa é de conhecimento apenas àqueles que possuem autoridade, as chances de elas desenvolverem seu potencial criativo ficarão significativamente reduzidas (GARDNER, 1996).

Diante do exposto, é possível pensar sobre o uso de estratégias e métodos que o professor pode utilizar em sala de aula, favorecendo à exploração e a descobertas de coisas sobre o mundo. Nessa exploração, o aluno encontrará meios e modos para as suas construções e para as suas respostas, onde fazendo o uso livremente da tesoura e do papel, por exemplo, o aluno poderá realizar diferentes construções, obras, recortes. A partir disso, uma estratégia que o professor pode utilizar para e com seus alunos, é a investigação. Através da investigação, o aluno explorará seus materiais, criará ideias e respostas para que se chegue ao resultado.

Periódico Horizontes - USF - Itatiba, SP-Brasil - e019009 


\section{Investigação e criatividade}

Considerando o trabalho investigativo em sala de aula como uma estratégia desenvolvida pelo professor, que instiga seus alunos a buscarem respostas as suas perguntas, oportunizando que desenvolvam autonomia e senso crítico, permitindo-lhes que se posicionem perante situações e problemas. Dessa forma, ao trabalhar com a investigação em sala de aula, o professor estará auxiliando também, no desenvolvimento do potencial criativo de seus alunos.

Sabendo que há estratégias, como a investigação, que desenvolvem a autonomia nos estudantes, assim como auxilia o desenvolvimento do potencial criativo nos alunos, surgem as seguintes indagações: por que os professores ainda fazem uso do método tradicional em sala de aula? Por que a escola muitas vezes, não permite que os alunos exprimam suas ideias e seus diferentes modos de pensar?

Essas interrogações relembram a invenção do iglu, citado por Alves (2007), onde é possível perceber que a resolução de problemas foi de fato bem sucedida, pois a criação do iglu supriu as necessidades daquele que o criou. Porém, a criatividade não se baseia apenas em uma resolução de problema, pois "toda situação em que entramos pode ser considerada problema e cada decisão, solução" (KNELLER, 1999, p. 24). A resolução de problemas só será criativa, se houver a criação de algo que se fez necessário naquele momento, a partir do uso dos materiais disponíveis, mas que continuará a ser útil para outras pessoas, povos, culturas, como foi o caso do iglu.

E para provocar o aluno a refletir e criar diferentes formas de solucionar problemas, desconhecidas pelo professor, pode-se fazer uso da investigação como uma estratégia de ensino e de aprendizagem, que auxilie o professor a instigar seus alunos a problematizar, sair do óbvio e prático, para algo que seja mais aprimorado (AZEVEDO, 2009). Sugerir "porquês" sem necessariamente ter uma ou mais respostas para todas as dúvidas é fundamental nesse processo.

Dessa forma, é preciso que o professor seja um facilitador da prática investigativa, validando as ideias e teorias que seus alunos formulam, não bloqueando ou criticando Periódico Horizontes - USF - Itatiba, SP-Brasil - e019009 
negativamente os diferentes modos de pensar. E sim, procurando auxiliar positivamente na construção do aprendizado dos alunos.

\section{Considerações finais}

A partir desse estudo é possível perceber que a utilização da investigação como uma estratégia de ensino em sala de aula, pode auxiliar no desenvolvimento do potencial criativo nos alunos. Esse por sua vez, pode ser necessário no dia-a-dia enquanto criança, quando adolescente, e mais tarde, quando adulto.

Todo ser humano encontra adversidades no seu cotidiano, seja por questões pessoais ou sociais. Contudo, um problema que se encontra com frequência, pode ser resolvido de diversas formas, inovar o seu modo de ver essa adversidade, e procurar pensar em outras formas de solucionar, assim se evidencia a criatividade.

Pensando na criatividade como algo que permite inovar, modificar algo que já está imposto socialmente como correto, pensar e refletir além do que se vê, buscando diversas possibilidades que leve a uma solução, ou a uma nova criação, pode-se considerar que é algo muito útil nos dias atuais, pois é preciso inovar o modo de pensar para se destacar como profissional, evitando fazer o que a maioria já o faz. Muitas vezes é preciso ser a minoria para que se tenha êxito, para que se faça um trabalho diferenciado no meio de atuação.

Entende-se que a criatividade é importante no dia-a-dia de todas as pessoas, sendo a investigação uma estratégia que, quando praticada, auxilia o aluno a ter ideias originais e criativas com o objetivo de elaborar hipóteses e chegar a resultados para o possível problema em questão.

\section{Referências}

ALENCAR, E. M. L. S. O estímulo à criatividade no contexto universitário. Psicologia Escolar e Educacional, Campinas, v. 1, n. 2-3, p. 29-37, 1997. Disponível em: http://www.scielo.br/scielo.php?script=sci_arttext\&pid=S1413-

Periódico Horizontes - USF - Itatiba, SP-Brasil - e019009 
$85571997000100004 \&$ Ing=en\&nrm=iso\&tlng=pt. Acesso em: 23 de jan. de 2018.

ALVES, R. Estórias de quem gosta de ensinar: o fim dos vestibulares. 11. ed. São Paulo: Papirus, 2007.

AZEVEDO, M. C. P. S. Ensino por Investigação: problematizando as atividades em sala de aula. In: CARVALHO, Anna M. P. (Org). Ensino de ciências: Unindo a Pesquisa e a Prática. São Paulo: Cengage learning, 2009, cap. 2, p. 19-33.

DEBOER, G. E. Historical Perspectives on Inquiry Teaching in Schools. In: FLICK, Lawrence; LEDERMAN, Norman G. (Ed.). Scientific Inquiry and Nature of Science: Implications for Teaching, Learning, and Teacher Education. Dordrecht, Netherland: Springer, 2006, p. 17-35.

FERRAZ, A. T.; SASSERON, L. H. Espaço Interativo de Argumentação Colaborativa: condições criadas pelo professor para promover argumentação em aulas investigativas. Ensaio Pesquisa em Educação em Ciência. vol.19, Belo Horizonte, 2017. Disponível em: http://www.scielo.br/scielo.php?script=sci_arttext\&pid=S1983-

$21172017000100215 \& \operatorname{lng}=$ pt\&nrm=iso. Acesso em: 15 de jan. de 2018.

GARDNER, H. Arte, Mente e Cérebro: Uma abordagem cognitiva da criatividade. Tradução de Sandra Costa. 1.ed. Porto Alegre: Artmed, 1999.

GARDNER, H. Mentes que Criam: Uma Anatomia da Criatividade Observada Através das Vidas de Freud, Einstein, Picasso, Stravinsky, Eliot, Graham e Gandhi. Tradução de Maria Adriana Veronese. 1.ed.. Porto Alegre: Artes Médicas, 1996.

GIL, A. C. Como elaborar projetos de pesquisa. 5. ed. São Paulo: Atlas, 2010.

KNELLER, G. F. Arte e Ciência da Criatividade. Tradução de José Reis. 14. ed. São Paulo: Ibrasa, 1999.

LAKATOS, E. M.; MARCONI, M. A. Fundamentos de metodologia científica. 4. ed. rev. ampl. São Paulo: Atlas, 2010.

MUMFORD, D.; LIMA, M. E. C. C. Ensinar ciências por investigação: em quê estamos de acordo? Ensaio Pesquisa em Educação em Ciências. v. 9, n. 1, Belo Horizonte, 2007, p. 89-111.

Disponível em: http://www.scielo.br/pdf/epec/v9n1/1983-2117-epec-9-01-00089.pdf. Acesso em: 18 de jan. de 2017.

NAKANO, T. C. Programas de treinamento em criatividade: conhecendo as práticas e resultados. Psicologia Escolar e Educacional, Maringá, São Paulo, v. 15, n. 2, p. 311-322, 2011. Disponível em: http://www.scielo.br/scielo.php?script=sci_arttext\&pid=S1413-

Periódico Horizontes - USF - Itatiba, SP-Brasil - e019009 
85572011000200013. Acesso em: 17 de jan. de 2018.

SILVA, J. S. O planejamento no enfoque emergente: uma experiência no 10 ano do Ensino Fundamental de nove anos. 2011. $237 \mathrm{f}$. Tese (Doutorado). Universidade Federal do Rio Grande do Sul, Programa de Pós-graduação em Educação, Porto Alegre, fev. 2011.

TUDDA, L.; SANTOS, A. B. A. Teorias para desenvolvimento da criatividade individual e organizacional. Revista Administração em Diálogo, São Paulo, v. 13, n. 1, p.116-133, 2011. Disponível em: https://revistas.pucsp.br/index.php/rad/article/view/3846. Acesso em: 18 de jan. de 2018.

WECHSLER, S. M. Avaliação multidimensional da criatividade: uma realidade necessária. Psicologia Escolar e Educacional, São Paulo, v. 2, n. 2, p. 89-101, 1998. Disponível em: http://www.scielo.br/scielo.php?script=sci_arttext\&pid=S1413-85571998000200003. Acesso em: 25 de jan. de 2018.

Recebido em março de 2018.

Aprovado em junho de 2018. 